\title{
Spectrum of Disease and Prescription Pattern for Outpatients with Neurological Disorders: An Empirical Pilot Study in Bangladesh
}

\author{
Md. Sahab Uddin ${ }^{\mathrm{a}}$ Abdullah Al Mamun ${ }^{\mathrm{a}}$ Md. Asaduzzaman ${ }^{\mathrm{a}}$ Fakhrul Hosn ${ }^{\mathrm{a}}$

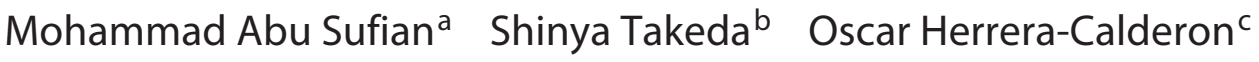 \\ Mohamed M. Abdel-Daim ${ }^{d}$ G.M. Sala Uddin ${ }^{a}$ Md. Ali Asif Noor ${ }^{a}$ \\ Mst. Marium Begum ${ }^{\mathrm{e}}$ Md. Tanvir Kabirf Sonia Zaman ${ }^{\mathrm{a}}$ Md. Shahid Sarwarg \\ Md. Mosiqur Rahman a Md. Rajdoula Rafe ${ }^{a}$ Md. Farhad Hossain ${ }^{h}$ \\ Md. Sarwar Hossain ${ }^{a}$ Mohammed Ashraful lqbal ${ }^{i}$ Md. Ataur Rahman Sujan ${ }^{j}$
}

${ }^{a}$ Department of Pharmacy, Southeast University, Dhaka, Bangladesh; ${ }^{b}$ Department of Clinical Psychology, Tottori University Graduate School of Medical Sciences, Tottori, Japan; ' Academic Department of Pharmaceutical Sciences, Faculty of Pharmacy and Biochemistry, Universidad Nacional San Luis Gonzaga de Ica, Ica, Peru; ${ }^{\text {Pharmacology }}$

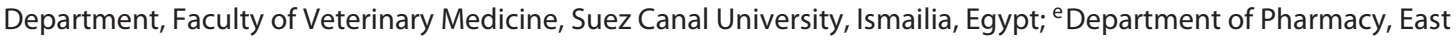
West University, Dhaka, Bangladesh; fDepartment of Pharmacy, BRAC University, Dhaka, Bangladesh; ${ }^{9}$ Department of Pharmacy, Noakhali Science and Technology University, Noakhali, Bangladesh; h Department of Physical Therapy, Graduate School of Inje University, Gimhae, South Korea; 'Department of Chemistry, Fareast International University, Dhaka, Bangladesh; 'Department of Pharmacy, University of Asia Pacific, Dhaka, Bangladesh

\section{Keywords}

Neurological disorders · Outpatients · Nonsteroidal anti-inflammatory drugs · Multivitamins · Multiminerals · Health care $\cdot$ Hospital pharmacy $\cdot$ Community pharmacy

\begin{abstract}
Background: Neurological disorders represent one of the most prominent causes of morbidity and mortality that adversely affect the lifestyle of patients and a major percentage of these diseases exists in developing countries. Purpose: The objective of this study was to examine the prevalence and prescription pattern for outpatients with neurological disorders in Bangladesh. Methods: The study was conducted on 1,684 patients in 6 hospitals (National Institute of Neurosciences and Hospital, Dhaka Medical College and Hospi-
\end{abstract}

tal, Bangabandhu Sheikh Mujib Medical University, Shaheed Suhrawardy Medical College, Sir Salimullah Medical College, and Apollo Hospitals Dhaka) of the Dhaka City from March 2014 to June 2015. Data were collected through a predesigned questionnaire from the patients that contain information about gender, age, marital status, occupation, residential status, affected disease, self-medicated medicines, and prescribed medicines. Results: Out of 1,684 patients, $28.38 \%$ patients were aged $51-60$ years and male, $57.19 \%$ predominance. The study exposed headache and migraine for $29.75 \%$ patients, followed by stroke for $23.93 \%$ patients and seizure for $7.07 \%$ patients. Genetic reason for the neurological disorders was seen only among $12.35 \%$ patients. In

M.S.U. and A.A.M. are equal contributors.

\section{KARGER}

(C) 2017 S. Karger AG, Basel

E-Mail karger@karger.com

www.karger.com/aon
Md. Sahab Uddin

Department of Pharmacy

Southeast University

Dhaka 1213 (Bangladesh)

E-Mail msu-neuropharma@hotmail.com,msu_neuropharma@hotmail.com 
this study, $16.98 \%$ patients had been affected by neurological disorders for more than 2 years and 19\% of patients for less than 6 months. Most extensively prescribed medicines were multivitamins and multiminerals used by $17.89 \%$ of patients followed by nonsteroidal anti-inflammatory drugs and other analgesic by $14.84 \%$; afterwards antiulcerants were used by $12.62 \%$, subsequently anticoagulants were used by $11.61 \%$ followed by antihyperlipidemic medicines by $10.26 \%$ and antiepileptic drugs by $8.08 \%$ of patients. The crucial reasons for the selection of prescribed medicines were the confidence that patients had with the physician's prescribed medicines, which was shown for $40.97 \%$ patients and knowledge of the medicines was reported for $35.04 \%$ patients. The period of prescribed medicine usage was 1-3 months for $39.73 \%$ patients and 3-6 months for $29.16 \%$ patients. The patient's compliance for prescribed medicines was satisfactory for $34.56 \%$ patients, good for $28.15 \%$ patients, and side effects were reported for $23.22 \%$ patients. Conclusion: In Bangladesh, it is not surprising to note that neurological diseases are more prevalent than other different diseases among different age groups and genders. Headache and migraine, stroke and seizure are most frequently encountered neurological disorders here. Treatment procedure of these disorders is not quite suitable due to the anomalies of health care management systems. Appropriate management of the health care system, especially the placement of hospital and community pharmacy can overcome the existing inconsistencies as well as increase the knowledge, awareness, and perception of the patients about health and neurological disorders.

(c) 2017 S. Karger AG, Basel

\section{Introduction}

Neurological disorders represent one of the most prominent causes of disability at the global level. Any abnormalities such as structural, biochemical, or electrical occur in the brain, spinal cord, cranial nerves, peripheral nerves, nerve roots, autonomic nervous system, neuromuscular junction, and muscles are greatly accountable for neurological disorders [1]. All over the world about 100 million of people are affected by neurological disorders [2]. Neurological disorders make up about $20 \%$ of the global burden of disease [3]. In 2005, globally the outbreak of neurological disorders was 155.36 per 1,000 population [4]. In line with the predictions of the United Nations, by 2025 about 1.2 billion elderly people will be affected by neurological disorders and $71 \%$ will be living in developing countries [4]. Neurological disorders ex- plained $3 \%$ of global disability-adjusted life-years (DALYs) and 5.6\% of global years lived with disability [5]. In 2005, neurological disorders contributed to 92 million DALYs and are expected to increase to 103 million in $2030[6,7]$.

There are more than 600 diseases of the nervous system [8]. Universally common neurological disorders are epilepsy, Alzheimer's disease (AD), and other dementias, headache, migraine, multiple sclerosis (MS), neuroinfections, Parkinson's disease (PD), stroke, brain tumors, brain trauma, malnutrition-related neurological disorders, and so on, [9-12]. Neurological disorders can be life threatening, similar to brain tumors and strokes or less harmful, similar to tension headaches and sleep disorders [13]. The worldwide prevalence of neurological disorders is high [14]. Among all the neurological disorders, epilepsy is regarded as one of the most common universal neurological disorder. According to World Health Organization (WHO), approximately 50 million people are affected by epilepsy all over the world [15]. In developing and lowincome countries, the prevalence of epilepsy is about $80 \%$ [16]. Dementia is considered the 3rd foremost cause of death in the United Kingdom, and almost 47.5 million people are living with dementia in the world. Consistent with the forecasts of WHO by 2030, the number of patients with dementia is likely to increase to about 75.6 million [17-19]. Statistics showed that every year about 6.7 million people are dying owing to stroke, which is one of the principal causes of death in developing countries and stroke accounts for more than $80 \%$ of deaths $[20,21]$. Headache disorders are also the most common disorders of the nervous system [22]. There are various types of headache disorders; usually the percentage of the adult population with headache is $47 \%$, followed by $38 \%$ of tension-type headache, followed by $3 \%$ of chronic headache and $10 \%$ of migraine that persists for more than 15 days per month [23].

WHO stated that approximately $20 \%$ of adults aged 60 and over are affected by neurological or mental disorders [24]. Dementia and depression are the most common neurological disorders seen in older patients [24, 25]. Among adults aged over 60s, neurological and mental disorders contributing to $6.6 \%$ of all DALYs [24]. In 2007, according to the report of the United Nations, up to 1 billion people, almost one in 6 of the world's population are affected from $\mathrm{AD}, \mathrm{PD}, \mathrm{MS}$, strokes, epilepsy, migraine, brain injuries, and neuroinfections [26]. This report also states that about 6.8 million are dying each year mainly due to the aforementioned diseases. In fact, $\mathrm{AD}$ is the most common reason of dementia and may affect up to $60-70 \%$ of cases [24]. In 2012, as per the Alzheimer's As-
Uddin et al. 
sociation (AA), 5.4 million Americans were affected by $\mathrm{AD}$. The number of Alzheimer's patients will be between 11 and 16 million as per AA estimates, with one new event happening every 33 s by 2050 in the United States [27]. Depression, especially unipolar among over 60 year olds, accounts for $5.7 \%$ of years lived with disability $[24,28$, 29]. It is most commonly seen in developing countries. According to $\mathrm{WHO}$, unipolar depression is regarded as the 3rd prominent cause of disease burden all over the world [24, 28, 29].

Albeit brain tumor, cerebral palsy, encephalopathy, headaches, metabolic diseases, and movement disorders are common neurological disorders affecting children; malnutrition-related disorders such as beriberi, polyneuropathy, polyneuropathy, cognitive dysfunction, Wernicke's encephalopathy, and so on, are also increasing. In low-income and developing countries wasting and stunting among children are common [4]. The prevalence of wasted children in low-income countries is $8 \%$ as per estimates by WHO [30]. In Latin America, the prevalence of wasted children is only $2 \%$, but in developing countries such as Bangladesh, it is $16 \%[31,32]$. In Bangladesh, stunting is also well-known to account for $45 \%$; however, it is only $14 \%$ in Latin America [33]. In low-income and developing countries, the global average for stunting among children is $32 \%$ [34]. Actually, childhood malnutrition is one of the main risk factors for DALYs and years of life lost [35]. In 2012, the Centers for Disease Control stated that autism and autism spectrum disorders have been identified in case of 1 in 68 children aged 8 years living in the United States [36].

Bangladesh is a developing country in which neurology was established as a new field in the 1960s [37, 38]. In July 2016, the population of Bangladesh was estimated to be 156,186,882 [39]. This country currently has an overall life expectancy of 73.2 years with male life expectancy of 71 years and female life expectancy of 75.4 years in 2016 [39]. Bangladeshi people lead a good life. The most common diseases of this country are stroke, malnutrition, and infectious diseases. Except for the aforementioned diseases, a large number of the population is affected by neurological disorders [37]. The condition of neurological disorders in Bangladesh is totally diverse from industrialized countries. Factors related to the social, psychological, and biological areas are greatly responsible for the level of mental health a person has at any point of time. In the developed countries, older adults are more prone to elder abuse like physical, mental or emotional, economical or material, abandonment, neglect and serious loss of dignity and respect [40]. Recent statistics show that 1 in 10 older people are linked with elder abuse [40]. Elder abuse is mainly responsible for long-lasting mental consequences, such as depression and anxiety as well as physical injuries [40]. Although Bangladesh is a low-income country, elder abuse is not common. In this country, a large number of people with common neurological disorders are not able to avail proper treatment due to poverty. Apart from the aforesaid problem, the sociocultural environment influences diagnosis thereby making treatment more difficult. In addition to this, most of the people living in rural areas are facing lack of required health care services [41]. In accordance with the international standard health care system, there is a close collaboration of pharmacists, physicians and nurses. But in Bangladesh, it is not well practiced. Here, the main inconsistency is the absence of pharmacists, who are not only drug specialists but also disease specialists.

Previously, there was no study that showed the pattern of outpatient's neurological diseases and their prescription trends. Therefore, the objective of this study was to analyze disease and prescription patterns for outpatients with neurological disorders in Bangladesh.

\section{Methods}

Study Site

The study site was Dhaka City Corporation, which is the capital of Bangladesh. It is the mega city of Dhaka District and Dhaka Division. The Dhaka Metropolitan area is the 11th largest city in the world with a population of 17 million people living in an area of $1,528 \mathrm{~km}^{2}$ [42]. There are about 194 hospitals in this city. These 6 hospitals include National Institute of Neurosciences and Hospital, Dhaka Medical College and Hospital, Bangabandhu Sheikh Mujib Medical University, Shaheed Suhrawardy Medical College, Sir Salimullah Medical College, and Apollo Hospitals Dhaka. These hospitals were selected for collection of data because these are the foremost hospitals of Dhaka City.

\section{Study Design}

This is a prescription-based, cross-sectional study that was conducted among outpatients with neurological disorders selected from the neurology department of 6 hospitals in Dhaka City. The period of this study was between March 2014 and June 2015. During this period, a total of 1,684 patients with neurological disorders were identified. The study protocol was approved by the Ethics Committee of the Department of Pharmacy, Southeast University, Dhaka, Bangladesh.

\section{Data Collection}

Each interested patient shared his or her disease history and prescriptions. Information about patient, disease, and medicine was collected in a predesigned questionnaire. The summary of information is listed in Table 1. Prior to the study, written consent was obtained from each patient. 
Table 1. List of collected information

Patient-related information
Gender
Age
Marital status
Occupation
Residential status

Disease-related information

Patients with neurological disorders

Family history

Duration of disorders

Previous measures of disorders

Patients follow-up

Compliance of previous measures

Non-neurologic disorders

Medicine-related information

Used self-medicated medicines

Neurological disorders that enforced self-medication

Reason of self-medication

Duration of self-medication

Compliance of self-medication

Used prescribed medicines

Reason of prescribed medicines

Duration of prescribed medicines

Compliance of prescribed medicines

Table 2. Demographic profile of the patients $(n=1,684)$

\begin{tabular}{lr}
\hline Variable & $\%$ \\
\hline Gender & \\
Male & 57.19 \\
Female & 42.81 \\
Age, years & \\
$<10$ & 0.95 \\
$11-20$ & 5.52 \\
$21-30$ & 16.98 \\
$31-40$ & 16.09 \\
$41-50$ & 18.53 \\
$51-60$ & 28.38 \\
$>60$ & 13.54 \\
Marital status & \\
Married & 65.08 \\
Unmarried & 34.92 \\
Occupation & \\
Students & 20.78 \\
Office workers & 25.59 \\
Day laborers & 19.48 \\
Householders & 16.45 \\
Retirees & 13.42 \\
Others & 4.28 \\
Residential status & \\
Urban & 82.84 \\
Rural & 17.16 \\
\hline
\end{tabular}

\section{Ethical Considerations}

The study protocol was approved by the Ethics Committee of the Department of Pharmacy, Southeast University, Dhaka, Bangladesh. The study was conducted in accordance with the ethical standards laid down in the 1964 Declaration of Helsinki.

Scope for Error

Since the study was based on the answers provided by the patients and their prescriptions not based on any laboratory test, there was no scope for error unless they provided misinformation.

Statistical Analysis

Results were collected and finally compiled and presented. Microsoft Excel 2010 (Roselle, IL, USA) was used for the statistical and graphical evaluations.

\section{Results}

Out of 1,684 patients, $57.19 \%$ were male and the remaining $42.81 \%$ were female. The majority of the patients $(28.38 \%)$ attending the neurology department belonged to 51-60 years age group. A majority of them were married $(65.08 \%)$. With regard to the work front, $25.59 \%$ patients were office workers and a majority of the patients $(82.84 \%)$ lived in urban areas. Detailed-patient related information is provided in Table 2.

In this study, $22.98 \%$ patients were affected with headache and $0.89 \%$ patients were affected by hydrocephalus as given in Table 3 . In case of $12.35 \%$ patient's family history was reported (Fig. 1). The duration of disease in a maximum number of patients (37\%) was 1 year as shown in Figure 2. Only 33.02\% patients took previous measures by going through a physician check-up against respective neurological disorders as shown in Figure 3. Follow-up details of the patients are given in Figure 4 in which physician follow-up was $54.31 \%$. Out of 575 patients (Fig. 4), $38.78 \%$ patients obtained partial recovery as depicted in Figure 5. In addition to neurological disorders, $17.46 \%$ patients were also affected by other non-neurological disorders as detailed in Figure 6.

The most widely used medicines that affected patients used by themselves were nonsteroidal anti-inflammatory drugs (NSAIDs) and other analgesics (27.77\%) as shown in Table 4. The foremost neurological disorders that enforced the patients to take self-medication were headache $(26.73 \%)$, ischemic stroke $(24.03 \%)$, and so on as given in Table 5. The main reason for self-medication was the preexperience, which was seen among $29.78 \%$ patients as shown in Figure 7. The duration of self-medication usage was found to be $3-6$ months in $41.79 \%$ of patients as given in Figure 8. Patients' compliance for self-medica- 


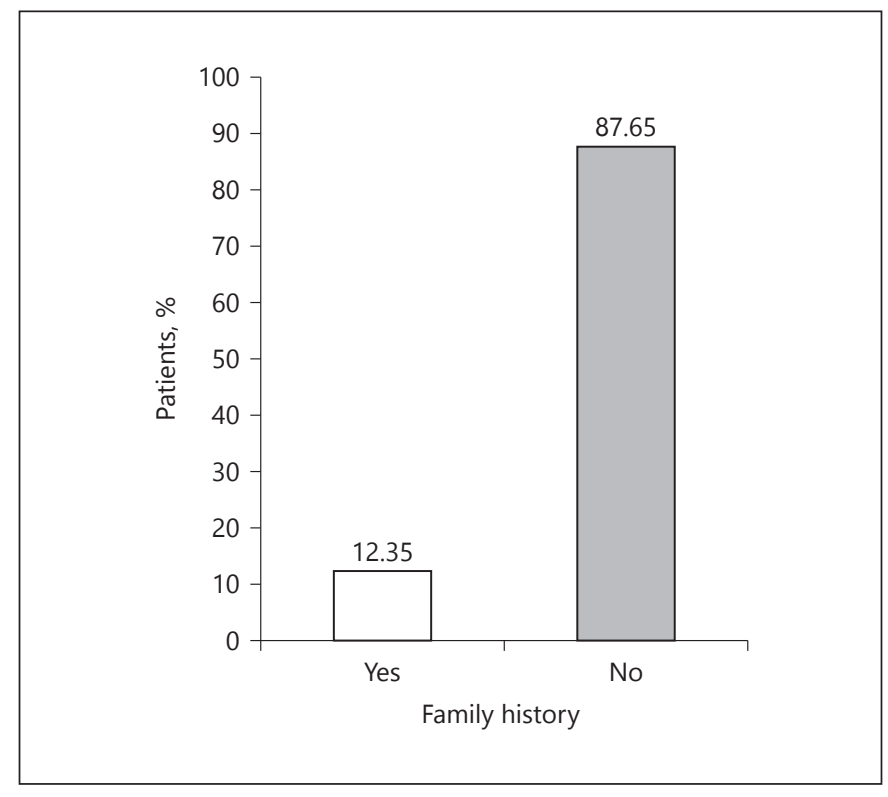

Fig. 1. Family history of neurological disorders among patients $(n=1,684)$. If a patient has a family history, it does not mean that the family history is responsible for the disorders.

tion varies from being excellent to being with side effects as given in Figure 9.

In this study, most widely prescribed medicines were multivitamins and multiminerals for $17.89 \%$ patients followed by NSAIDs and other analgesics for $14.84 \%$ patients as shown in Table 6 . The underlying reason that enforced the patients to take prescribed medicines was the confidence they had with the physician's prescribed medicines, which was seen among $40.97 \%$ patients as given in Figure 10. The duration of prescribed medicine usage was found to be a period of 1-3 months in $39.73 \%$ of patients (Fig. 11). About the patient's compliance for prescribed medicines, $34.56 \%$ patients stated that the disease recovery was satisfactory as given in Figure 12.

\section{Discussion}

Bangladesh is one of the densely populated countries in the world where infectious diseases, malnutrition, and many chronic neurological disorders are quite common [43]. This is the first study showing the prevalence of outpatients with neurological disorders and prescribing trends in Bangladesh.

The demographic profile of the patients of this study reflects that neurological disorders were more prevalent among the male (57.19\%), 41-60 years old (46.91\%) and all

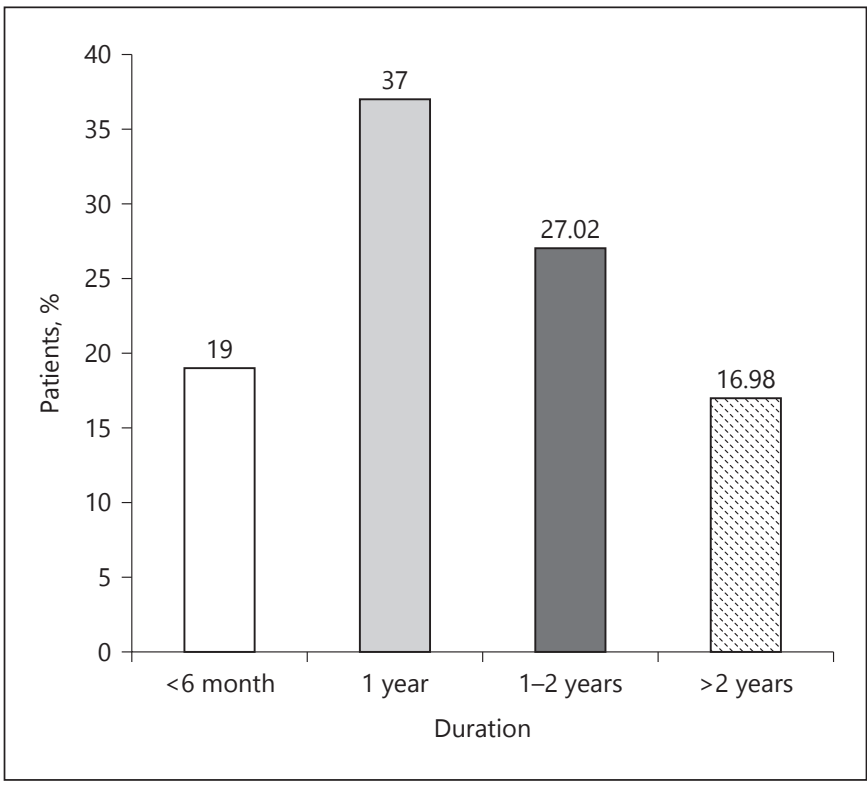

Fig. 2. Duration of neurological disorders among patients $(n=$ $1,684)$. The suffering duration of the patients ranges from less than 6 months to greater than 2 years.

Table 3. Foremost neurological disorders at outpatient departments $(n=1,684)$

\begin{tabular}{lr}
\hline Neurological disorders & $\%$ \\
\hline Headache & 22.98 \\
Migraine & 6.77 \\
Ischemic stroke & 17.64 \\
Hemorrhagic stroke & 6.29 \\
Subarachnoid hemorrhage & 1.13 \\
Transient ischemic attack & 0.95 \\
Focal seizure & 3.98 \\
Primary generalized seizure & 3.09 \\
Alzheimer's disease & 5.29 \\
Parkinson's disease & 1.66 \\
Dystonia & 1.43 \\
Peripheral neuropathy & 3.92 \\
Hydrocephalus & 0.89 \\
Myopathy & 1.54 \\
Paraplegia & 1.90 \\
Cranial nerve palsy & 1.07 \\
Lumber spondylosis & 2.55 \\
Cerebral palsy & 1.37 \\
Potts disease & 1.01 \\
Meningitis & 1.31 \\
Brain tumor & 1.96 \\
Encephalopathy & 1.13 \\
Cervical spondylosis & 1.30 \\
Transverse myelitis & 2.08 \\
Disc prolapse & 2.90 \\
Undiagnosed & 2.49 \\
Others & 1.37 \\
\hline & \\
\hline
\end{tabular}


Fig. 3. Previous measures for neurological disorders $(n=1,684)$. The activities (i.e., allopathic, herbal, unani, homeopathic medicine/no treatment) taken by the patients to treat or control their disease and/or discomforts before assignation with this study.

Fig. 4. Patients follow-up for neurological disorders $(n=812)$. The consecutive activities (i.e., allopathic, herbal, unani, homeopathic medicine practitioner/do not follow) taken by the patients to treat or control their disease and/or discomforts.
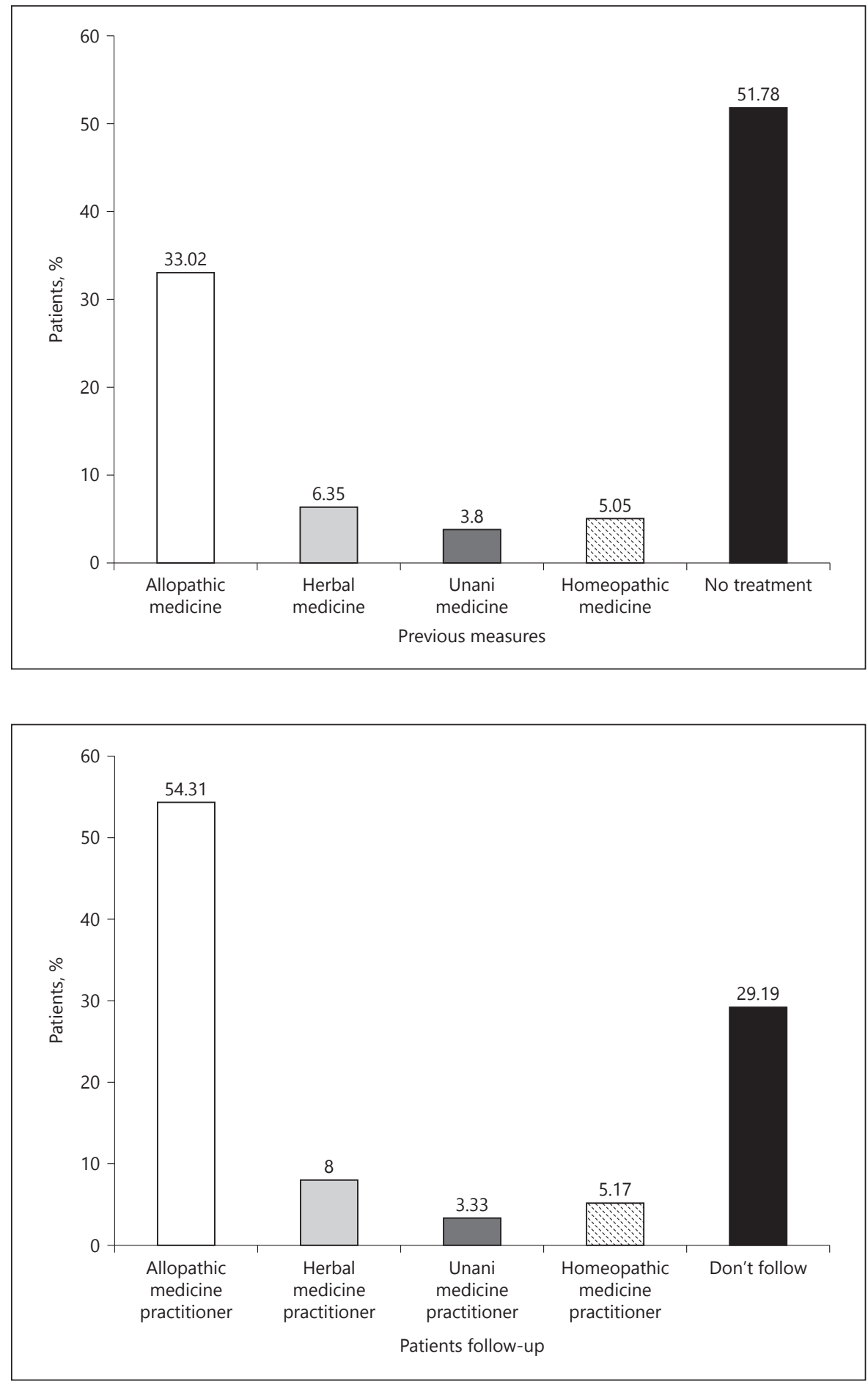

married people (65.08\%). Age-related prevalence neurological disorders are also more common in the developed world. In accordance with WHO, more than $20 \%$ of adults aged 60 and above 60 are found to be with neurological disorders as stated earlier [40]. Like other developing countries, mar- riage rate is also higher in this country. A study conducted by Gajurel et al. [44] in India showed similar findings in terms of age and gender. This study showed that office workers, students, day laborers, and householders were more prone to neurological orders. Murthy et al. [45] showed that 
Fig. 5. Compliance of previous measures for neurological disorders $(n=575)$. The outcomes (i.e., partial recovery, no recovery, worsened) obtained by patients owing to previous activities specified in Figure 3.

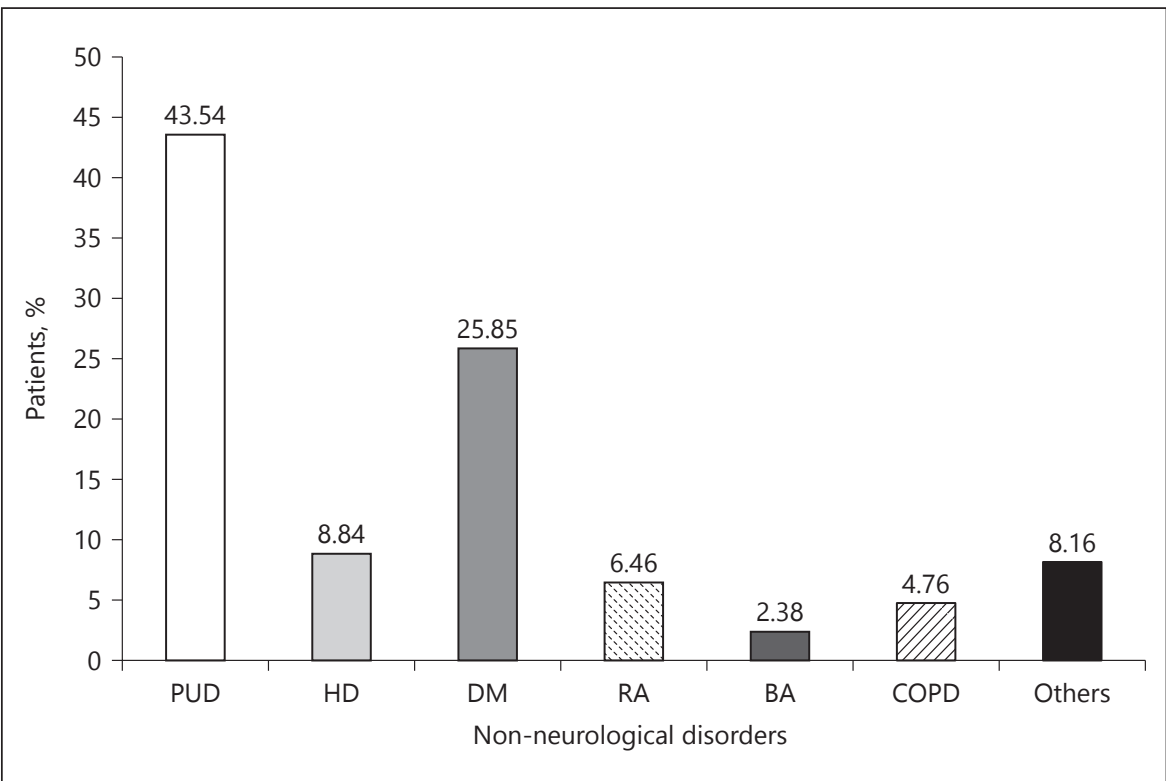

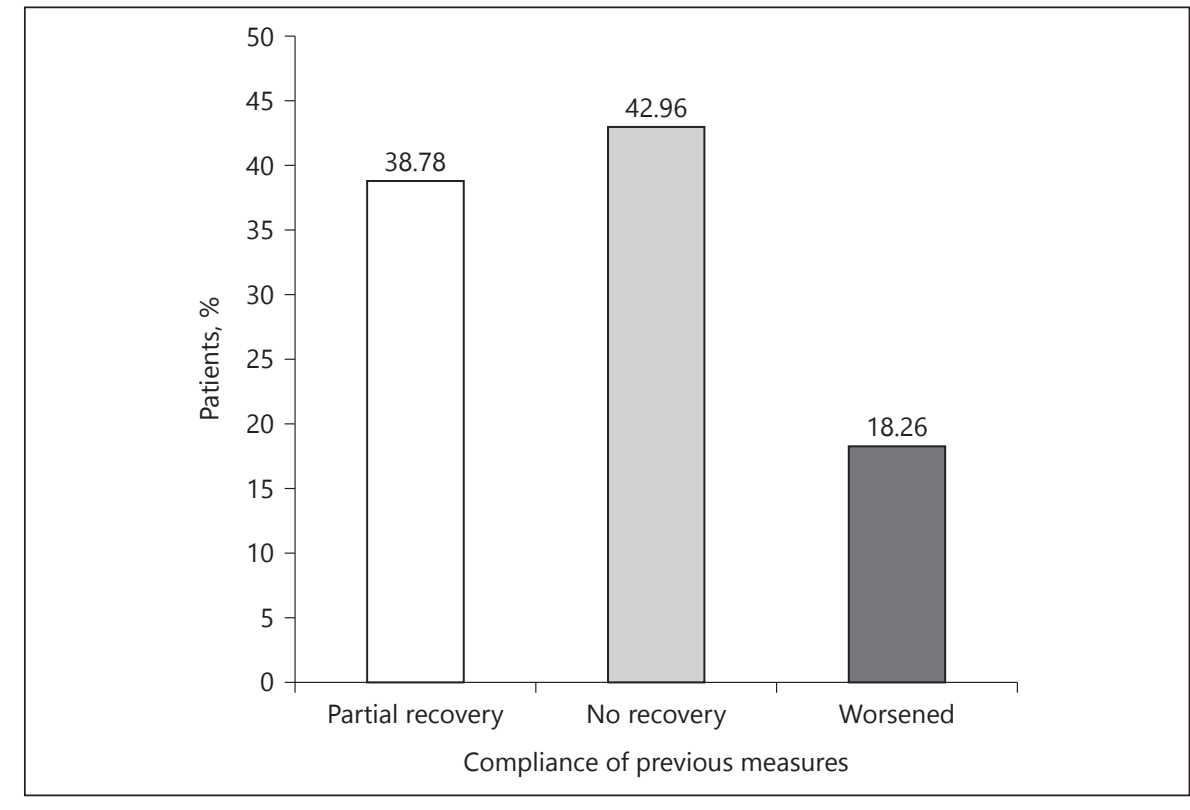

Fig. 6. Non-neurological disorders at outpatient department $(n=294)$. The negative outcome of the patients by ailments except neurological disorders. Here, PUD, peptic ulcer disease; HD, heart disease; DM, diabetes mellitus; RA, rheumatoid arthritis; $\mathrm{BA}$, bronchial asthma; COPD, chronic obstructive pulmonary disease.
Table 4. Used self-medicated medicines for neurological disorders $(n=1,030)$

\begin{tabular}{llr}
\hline Classes of the medicines & Self-medicated medicines & $\%$ \\
\hline NSAIDs and other analgesics & Aspirin, Naproxen, Ibuprofen, Ketorolac, Diclofenac, Indomethacin, Paracetamol & 27.77 \\
Antiulcerants & Antacids, Ranitidine, Famotidine, Omeprazole, Esomeprazole, Pantoprazole & 19.22 \\
Antimigraine & Zolmitriptan, Sumatriptan & 6.50 \\
Antihyperlipidemic & Atorvastatin, Simvastatin, Fenofibrate & 11.36 \\
Anticoagulants & Aspirin, Warfarin & 13.11 \\
Antihypertensive & Losartan, Atenolol, Propranolol, Carvedilol \\
Antiepileptic & Diazepam, Clonazepam, Carbamazepine, Lorazepam & 7.96 \\
\hline
\end{tabular}


Fig. 7. Reason of self-medication for neurological disorders $(n=591)$. Reasons behind the administration of medicines by self-assessment of the patients.

Fig. 8. Duration of self-medication for neurological disorders $(n=591)$. The period of self-medication practice of the patients ranges from less than 1 month to 6-12 months.
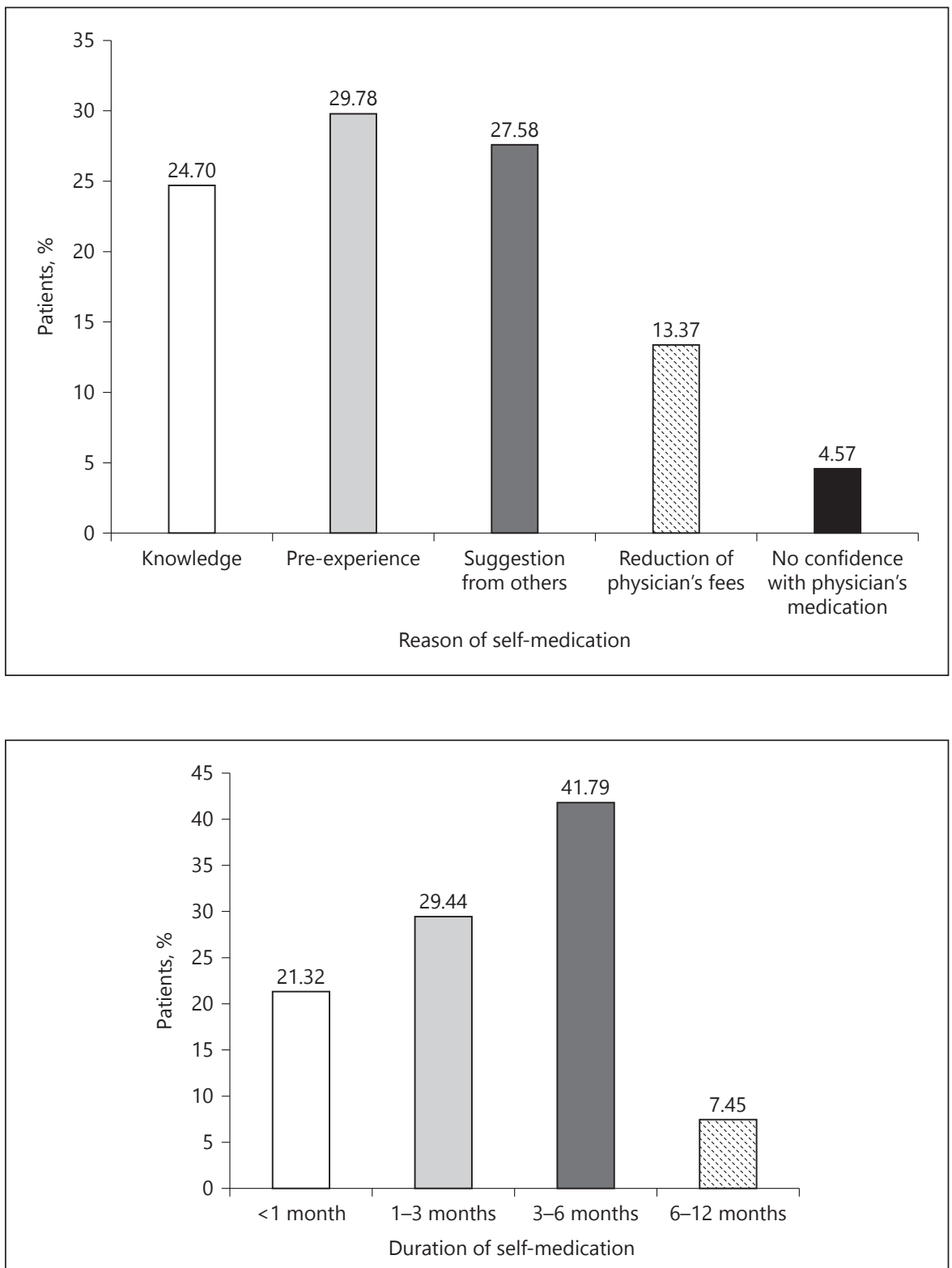

Table 5. Neurological disorders that enforced self-medication $(n=$ 591)

\begin{tabular}{lc}
\hline Neurological disorders & $\%$ \\
\hline Headache & 26.73 \\
Migraine & 14.55 \\
Ischemic stroke & 24.03 \\
Hemorrhagic stroke & 12.18 \\
Subarachnoid haemorrhage & 4.06 \\
Transient ischemic attack & 2.71 \\
Focal seizure & 8.8 \\
Primary generalized seizure & 6.94 \\
\hline
\end{tabular}

householders were mostly affected by epilepsy in India. This study showed that $82.84 \%$ patients lived in urban areas. According to the study of Gourie-Devi et al. [46], the prevalence rate of neurological disorders in urban and rural populations was 2,190 and 4,070/100,000, respectively, in India.

In case of developed countries, the most common neurological disorders are $\mathrm{AD}, \mathrm{PD}$, amyotrophic lateral sclerosis, stroke, traumatic brain injury, spinal cord injury, epilepsy, and so on. Stroke is considered a major killer and cause of disability in the developing world. The average annual incidence rate of stroke in India was 145 per 100,000 populations, which is higher than the western nations [47]. 


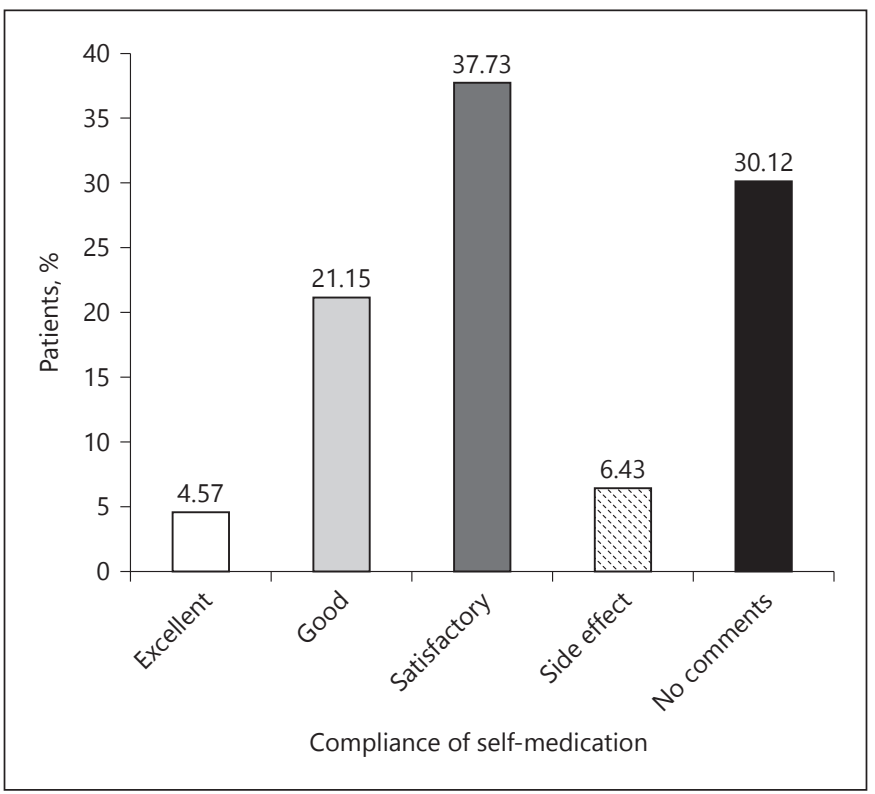

Fig. 9. Compliance of self-medication for neurological disorders $(n=591)$. The opinion of the patients taken self-medication ranges from excellent to side effect/no comments.

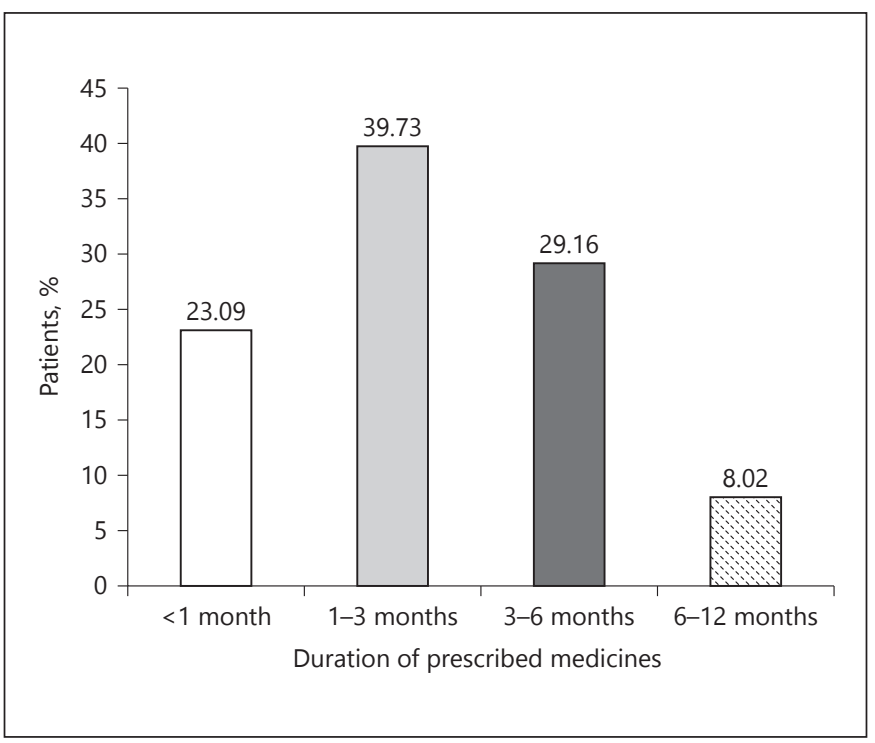

Fig. 11. Duration of prescribed medicines for neurological disorders $(n=1,684)$. The period of administration of prescribed medicines ranges from less than 1 month to 6-12 months.

In the United States, stroke is the 5th leading cause of death, killing nearly 129,000 people in a year and considered the leading cause of long-term severe disability [48]. In this study headache, migraine, stroke, and seizure were the foremost neurological disorders. As stated by the study of Mateen et al. [49], the majority of people with primary

Disease and Prescription Pattern for Outpatients with Neurological Disorders

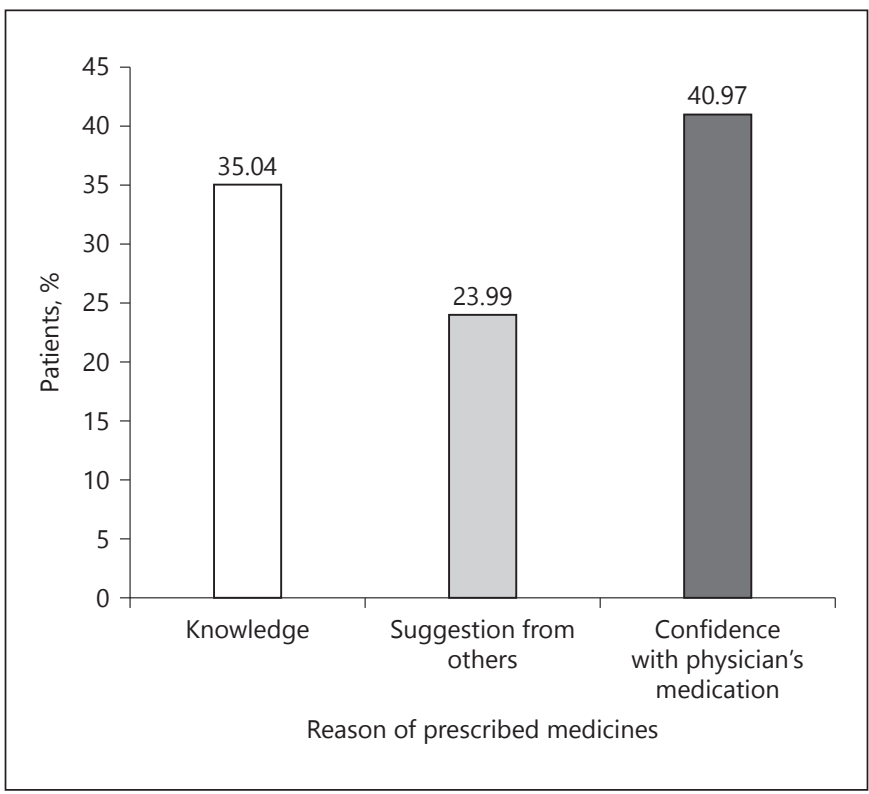

Fig. 10. Reason of prescribed medicines for neurological disorders $(n=1,684)$. The reasons behind the administration of medicines by physician assessment.

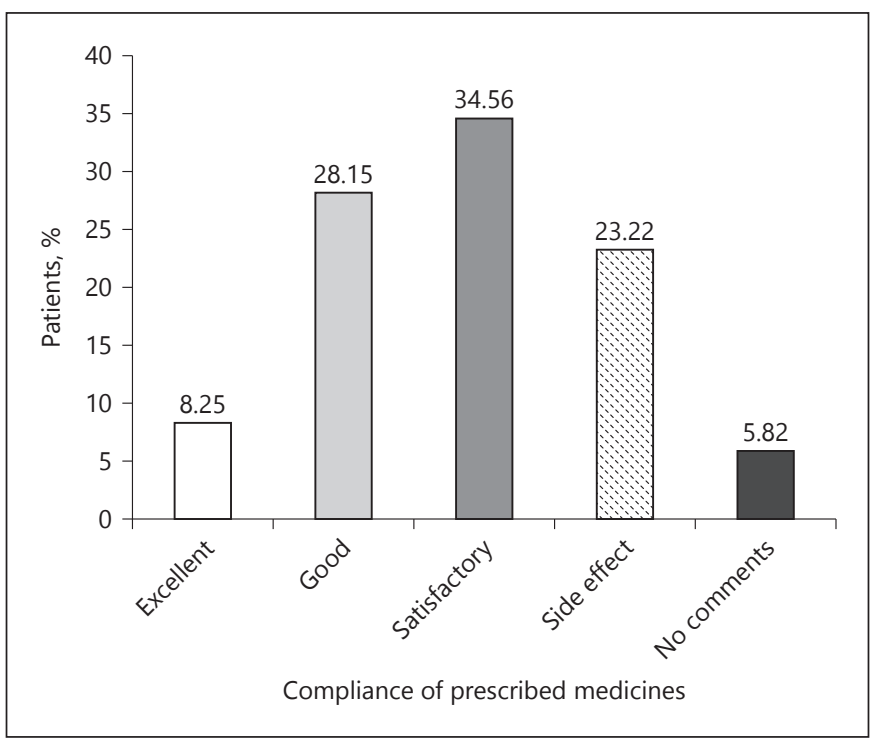

Fig. 12. Compliance of prescribed medicines for neurological disorders $(n=1,684)$. The opinion of the patients who have taken prescribed medicines ranges from excellent to side effect/no comments.

headache disorders lived in the developing world. In the study of prevalence and characteristics of the headache by Siddiqi et al. [50], showed that 30\% school- and collegegoing students had headache in Bangladesh. The study suggested that epilepsy affects 2.9 million people in the United States and 65 million people worldwide. Addition- 
Table 6. Used prescribed medicines for neurological disorders $(n=3,773)$

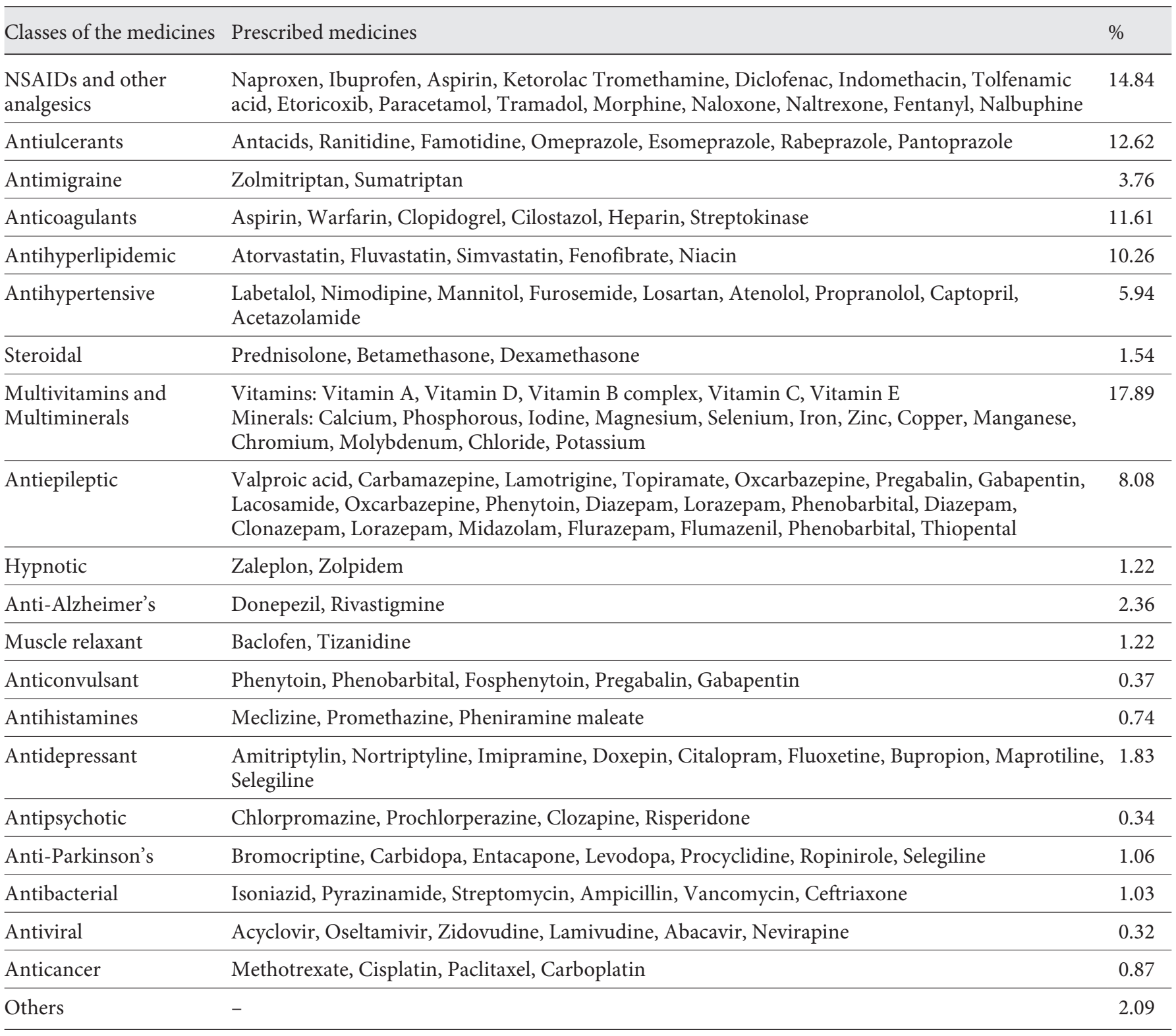

ally, about 1 in 26 people will experience recurring seizures [51]. The study of Mannan showed that the number of epilepsy patients in Bangladesh was about 1.3 million [52].

The folkloristic concepts of medicinal plants play an active role in the treatment of various medical conditions. In this study, $15.2 \%$ patients reported complementary and alternative medicine. The use of folk medicines is higher in rural areas of Bangladesh [53]. About 3.5 billion people in developing countries primarily relied on medicinal plants and herbal medicine around for their health care needs [54]. As indicated by WHO, more than $80 \%$ of the world's population trusts on traditional medicine for their medical care [55]. The study of Mannan showed that about $70 \%$ of patients visited indigenous medicine practitioners, exorcists, and spiritualists before to consulting a physician in Bangladesh [52]. In the study of the role of traditional healers and indigenous medical practitioners in health care by Nandan, it was found that nearly three-fourth of the indigenous medical practitioners (74.37\%) in the rural area of Agra were treating 15 patients in a day [56].

In this study, the medicines mostly used as self-medication were NSAIDs and other analgesics, antiulcerants, an- 
tiepileptic, anticoagulants drugs, and so on. The reason that enforced the patients to take NSAIDs and other analgesics as self-medication is their disease status. Moreover, due to the availability of medication like consumer products, selfmedication is not only limited to over-the-counter medicines that were proved by the self-medication patterns of the patients in this study. Day by day, medicines were changed from prescription-only medications to pharmacy medications. The prevalence rates of self-medication among university students are relatively high. Previous studies had reported prevalence rates of about $76 \%$ in Pakistan, $94 \%$ in Hong Kong, $87 \%$ in India, $43.2 \%$ in Ethiopia, 86.4\% in Brazil, 98\% in Palestine, and 55\% in Egypt [57]. According to this study, headache, ischemic stroke, migraine, hemorrhagic stroke, focal seizure, and so on were the neurological disorders for which self-medication was preferred. Sawalha showed that headache and flu were the most common health conditions for which self-medication was preferred in Palestine [58]. This study revealed that past experiences and suggestion from others were the main reasons for selecting self-medication. A previous study among university students of Bangladesh showed that the main reason for self-medication of analgesic or antipyretic was based on individual preferences and statuses [59]. In addition to these, financial factor is likely to partly accountable for self-medication. In the study of self-medication practice of Kolladiba town, North West Ethiopia by Abrha et al. [60] it was found that the high cost of modern health care was responsible for practising self-medicine. In developed countries, the rate of self-medication is very poor due to the existence of strict rules and regulation. The uncontrolled use of medicines can be harmful because of adverse drug reactions, although in this study, the compliance for self-medication was satisfactory for $37.73 \%$ patients.

The existing prescribing trends revealed that commonly prescribed medicines for neurological disorders were multivitamins and multiminerals, NSAIDs and other analgesics, antiulcerants, anticoagulants, antihyperlipidemic, antiepileptic, antihypertensive, and antimigrane medicines. The study of Kuriakose et al. [61] showed that antihypertensive drugs (32\%) followed by antiplatelet (14\%), neuroprotective (10\%), and nootropics (8\%) were prescribed drug for stroke in India [61]. Carbamazepine (13.3\%) was the first-line drug prescribed for simple partial seizures and complex partial seizures, according to the study of Murthy et al. [45] in India [61].

This study demonstrated various parameters in terms of neurological disorders and medicine-utilization patterns as well as reported numerous alarming situations that need to be marked for required action.

Disease and Prescription Pattern for Outpatients with Neurological Disorders

\section{Conclusion}

This study showed that headache and migraine, stroke, and seizure were more prominent diseases that are not comparable to the diseases prevalent in western countries where $\mathrm{AD}$ and other dementia are primary neurological diseases. As a developing country in addition to neurological disorders, peptic ulcer disease, diabetes mellitus, and heart disease were reported to be present among patients. NSAIDs and other analgesics, antiulcerants, antiepileptic, anticoagulants, and antihyperlipidemic were the most commonly reported types of medications consumed through self-medication. The commonly prescribed medicines for neurological disorders were multivitamins and multiminerals, NSAIDs, antiulcerants, anticoagulants, antihyperlipidemic, antihypertensive, antiepileptic, and antimigrane. In this study, side effects were reported among many patients. The study also revealed the presence of multivitamins and minerals in a number of prescriptions. In this study, the most frequent use of selfmedicated medicines, irrational uses of multivitamins and minerals were reported. The irrational use of medicines and side effects of medicines are mainly due to the health care setting of this country. Actually the health care system in Bangladesh is totally different. In western countries, most of the pharmacists are working as hospital and community pharmacists, but in Bangladesh, most of the pharmacists are industrial pharmacists and there are very few hospital pharmacists owing to the unavailability of hospitals and community clinic practices and management hierarchy of hospitals and community clinics. Medicine can save lives, but the people of this country deal with their life with great risks. Proper settings of the health care management system, especially the placement of hospital and community pharmacy can improve the health care facilities and save the life of the people of Bangladesh.

\section{Acknowledgments}

The authors wish to thank the anonymous reviewer(s)/editor(s) of this article for their constructive reviews. The authors are also grateful to the Department of Pharmacy, Southeast University, Dhaka, Bangladesh.

\section{Ethical Approval}

The study protocol was approved by the Ethics Committee of the Department of Pharmacy, Southeast University, Dhaka, Bangladesh. The study was conducted in accordance with the ethical standards laid down in the 1964 Declaration of Helsinki. 


\section{Disclosure Statement}

The authors declare no conflicts of interest. The manuscript complies with International Committee of Medical Journal Editor's guidelines.

\section{Funding Source}

This work was self-funded.

\section{Author Contributions}

This work was carried out in collaboration between all authors. M.S.U. designed the study, wrote the protocol, managed the analyses of the study, and prepared the draft of the manuscript. A.A.M. managed the literature searches and helped with M.S.U. to prepare the draft of the manuscript. A.A.M., F.H., M.A.S., G.M.S.U., M.A.A.N., M.M.B., M.T.K., M.F.H., M.S.H., M.A.I., and M.A.R.S. collected data. M.S.U., A.A.M., M.A., S.Z., M.S.S., M.M.R., and M.R.R. performed statistical and graphical evaluations. S.T., O.H.C., and M.M.A.D. participated in study design and reviewed the scientific contents of the manuscript. All the authors read and approved of the final manuscript.

\section{References}

1 Chin JH, Vora N: The global burden of neurologic diseases. Neurology 2014;83:349-351.

$\checkmark 2$ Burton KJ, Allen S: A review of neurological disorders presenting at a paediatric neurology clinic and response to anticonvulsant therapy in Gambian children. Ann Tropical Paediat 2003;23:139-143.

3 Burton KJ, Allen S: A review of neurological disorders presenting at a paediatric neurology clinic and response to anticonvulsant therapy in Gambian children. Ann Trop Pedi 2003;23 139-143.

4 Gourie-Devi M: Organization of neurology services in India: Unmet needs and the way forward. Neurol India 2008;56:4-12.

5 Whiteford HA, Ferrari AJ, Degenhardt L, Feigin V, Vos T: The global burden of mental, neurological and substance use disorders: an analysis from the global burden of disease study 2010. PLoS One 2015;10:e0116820.

-6 Bower JH, Asmera J, Zebenigus M, Sandroni P, Bower SM, Zenebe G: The burden of inpatient neurologic disease in two Ethiopian hospitals. Neurolo 2007;68:338-342.

-7 Tegueu CK, Nguefack S, Doumbe J, Fogang YF, Mbonda PC, Mbonda E: The spectrum of neurological disorders presenting at a neurology clinic in Yaoundé, Cameroon. Pan Afr Med J 2013;14:148.

8 Zlokovic BV: The blood-brain barrier in health and chronic neurodegenerative disorders. Neuron 2008;57:178-201.

9 Gourie-Devi M: Organization of neurology services in India: unmet needs and the way forward. Neurol India 2008;56:4-6.

10 Uddin MS, Asaduzzaman M, Mamun AA, Iqbal MA, Wahid F, Rony RK: Neuroprotective activity of Asparagus racemosus Linn. against ethanol-induced cognitive impairment and oxidative stress in rats brain: auspicious for controlling the risk of Alzheimer's disease. J Alzheimers Dis Parkinsonism 2016; 6:1-10.

11 Uddin MS, Mamun AA, Iqbal MA, Islam A, Hossain MF, Khanum S, Rashid M: Analyzing nootropic effect of Phyllanthus reticulatus Poir. on cognitive functions, brain antioxi- dant enzymes and acetylcholinesterase activity against aluminium-induced Alzheimer's model in rats: applicable for controlling the risk factors of Alzheimer's disease. Adv Alzheimer's Dis 2016;5:87-102.

12 Uddin MS, Mamun AA, Hossain MS, Ashaduzzaman M, Noor MA, Hossain MS, et al: Neuroprotective effect of Phyllanthus acidus L. On learning and memory impairment in scopolamine-induced animal model of dementia and oxidative stress: natural wonder for regulating the development and progression of Alzheimer's disease. Adv Alzheimer,s Dis 2016;5:53-72.

13 Cai Q, Wang L, Deng G, Liu J, Chen Q, Chen $\mathrm{Z}$ : Systemic delivery to central nervous system by engineered PLGA nanoparticles. Am J Transl Res 2016;8:749-764.

14 Birbeck GL, Meyer AC, Ogunniyi A: Nervous system disorders across the life course in resource-limited settings. Nature 2015;527: S167-S171.

15 Dekker PA: Epilepsy: A Manual for Medical and Clinical Officers in Africa, WHO. France, World Health Organization, 2002.

16 Birbeck GL: Epilepsy care in developing countries: art I of II. Epilepsy Curr 2010;10: 75-79.

17 Xu J, Wang J, Wimo A, Fratiglioni L, Qiu C: The economic burden of dementia in China, 1990-2030: implications for health policy. Bull World Health Organ 2017;95:18-26.

18 Abdullah AM, Uddin MS, Wahid F, Mohammed AI, Rahman MM: Neurodefensive effect of Olea europaea L. in alloxan-induced cognitive dysfunction and brain tissue oxidative stress in mice: incredible natural nootropic. J Neurology Neurosci 2016;7(suppl 3):1-9.

19 Uddin MS, Mamun AA, Sarwar MS, Chaity $\mathrm{NH}$, Haque A, Akter N, et al: Medicine that causes memory loss: risk of neurocognitive disorders. Int Neuropsych Dis J 2016;8:118.

20 Go AS, Mozaffarian D, Roger VL, Benjamin EJ, Berry JD, Borden WB, et al; American heart association statistics committee and stroke statistics subcommittee: Heart disease and stroke statistics-2013 update: a report from the American heart association. Circulation 2013;127:e6-e245

-21 Dreyer R, Murugiah K, Nuti SV, Dharmarajan K, Chen SI, Chen R, et al: Most important outcomes research papers on stroke and transient ischemic attack. Circ Cardiovasc Qual Outcomes 2014;7:191-204.

22 Ahmed F: Headache disorders: differentiating and managing the common subtypes. $\mathrm{Br} \mathrm{J}$ Pain 2012;6:124-132.

23 Stovner L, Hagen K, Jensen R, Katsarava Z, Lipton R, Scher A, et al: The global burden of headache: a documentation of headache prevalence and disability worldwide. Cephalgia 2007;27:193-210

24 Kaddumukasa M, Mugenyi L, Kaddumukasa MN, Ddumba E, Devereaux M, Furlan A: Prevalence and incidence of neurological disorders among adult Ugandans in rural and urban Mukono district; a cross-sectional study. BMC Neurol 2016;16:227.

-25 Uddin MS, Haque A, Mamun AA, Iqbal MA Kabir MT, Rony RK, et al: Searching the linkage between high fat diet and Alzheimer's disease: a debatable proof stand for ketogenic diet to alleviate symptoms of Alzheimer's patient with APOE $\varepsilon 4$ allele. J Neurol Neurophysiol 2016;7:1-9.

26 Gourie-Devi M: Organization of neurology services in India: unmet needs and the way forward. Neurol India 2008;56:4-12.

27 Alzheimer,s Association: Alzheimer's Disease facts and figures. Alzheimer's \& Dementia 2014;10:1-63.

28 Spaans HP, Pascal S, Bouckaert F, van den Berg JF, Verwijk E, Kho KH, et al: Speed of remission in elderly patients with depression: electroconvulsive therapy v. medication. $\mathrm{Br} \mathrm{J}$ Psychi 2015;206:67-68.

29 Verma RK, Min TH, Chakravarthy S, Barua A, Kar N: Sociodemographic correlates of unipolar major depression among the Chinese elderly in Klang Valley, Malaysia: an epidemiological study. Sci Wor J 2014;2014: $1-2$. 
-30 Christian P, Lee SE, Angel MD, Adair LS, Arifeen SE, Ashorn P, et al: Risk of childhood undernutrition related to small-for-gestational age and preterm birth in low- and middle-income countries. Int J Epidemiology 2013;42:1340-1355.

- 31 Post CL, Victora CG: The Low prevalence of weight-for-height deficits in Brazilian children is related to body proportions. J Nutr 2001;131:1290-1291.

32 Rahman MN, Mistry SK, Hossain MI: Nutritional status of child labourers in Dhaka city of Bangladesh: findings from a cross sectional study. Bangladesh J Chi Heal 2014;38:130136.

-33 de Onis M, Blössner M, Borghi E: Prevalence and trends of stunting among pre-school children, 1990-2020. Pub Heal Nutri 2012;15: 142-148.

-34 Kimani-Murage EW, Muthuri SK, Oti SO, Mutua MK, van de Vijver S, Kyobutungi C: Evidence of a double burden of malnutrition in urban poor settings in Nairobi, Kenya. PLoS One 2015;10:e0129943.

35 Wang $\mathrm{H}$, Naghavi M, Allen C, Barber RM, Bhutta ZA, Carter A, et al: Global, regional, and national life expectancy, all-cause mortality, and cause-specific mortality for 249 causes of death, 1980-2015: a systematic analysis for the global burden of disease study 2015. Lancet 2016;388:1459-1544.

-36 Christensen DL, et al: Prevalence and characteristics of autism spectrum disorder among children aged 8 years - autism and developmental disabilities monitoring network, 11 sites, United States, 2012. MMWR Surveill Summ 2016;65:1-23.

37 Chowdhury RN, Hasan AT, Ur Rahman Y, Khan SI, Hussain AR, Ahsan S: Pattern of neurological disease seen among patients admitted in tertiary care hospital. BMC Res Notes 2014;7:202:1-2.

38 Mateen FJ: International issues: neurology in Bangladesh. Neurology 2010;74:e5-e8.

39 Johnson JA, Stoskopf C, Shi L: Comparative Health Systems: A Global Perspective. ed 2, Burlington, Jones \& Bartlett Learning, 2017, p 385.
40 Dong X: Elder abuse: Research, practice, and health policy. The 2012 GSA Maxwell Pollack award lecture. Gerontologist 2013;54:153162.

41 Chowdhury RN, Hasan AT, Rahman KM, Shyfullah M, Deb SR, et al: Spectrum of neurological disorders: experience in specialized outpatient clinic in Bangladesh. J Med 2012; 13:39-42.

42 Alam MJ, Ahmad MM: Analysing the lacunae in planning and implementation: spatial development of Dhaka city and its impacts upon the built environment. Int J Urban Sustainab Develop 2010;2:85-106.

43 Streatfield PK, Karar ZA: Population challenges for Bangladesh in the coming decades. J Hea Pop Nutri 2008;26:261-272.

44 Gajurel BP, Parajuli P, Nepali R, Oli KK: Spectrum of neurological disorders admitted in Tribhuvan University teaching hospital Maharajgunj. J Inst Med 2012;34:50-53.

45 Murthy NV, Anusha B, Perumal P: A Study on trends in prescribing pattern of anti-epileptic drugs in teritiary care teaching hospital. Int J Che Pharmace Sci 2012;3:25-30.

46 Gourie-Devi M, Gururaj G, Satishchandra P, Subbakrishna DK: Prevalence of neurological disorders in Bangalore, India: a community based study with a comparison between urban and rural areas. Neuroepidemi 2004;23: 261-268.

47 Kaul S, Bandaru VC, Suvarna A, Boddu DB: Stroke burden and risk factors in developing countries with special reference to India. J Indian Med Assoc 2009;107:367-370.

48 Uddin MS, Asaduzzaman M, Mamun AA, Rashid M: Assessment of knowledge and awareness about atherosclerosis and incidence of cardiovascular events among undergraduate pharmacy students in Bangladesh. Br J Pharm Res 2016;9:1-13.

49 Mateen FJ, Dua T, Steiner T, Saxena S: Headache disorders in developing countries: research over the past decade. Cephalalgia 2008; 28:1107-1114.

50 Siddiqi MH, Hasibur MR, Hadiuzzaman, Yeasmin F, Yunus A: Prevalence and characteristics of headache assessed in Bangladeshi school and college going students. Comm Bas Med J 2012;1:14.

51 Rosenberg EC, Tsien RW, Whalley BJ, Devinsky O: Cannabinoids and Epilepsy. Neurotherapeutics 2015;12:747-768.

52 Mannan MA: Epilepsy in Bangladesh. Neuro Asia 2004;9(suppl 1):18.

53 Karmakar P, Islam MM, Kibria MG, Hossain MS, Sattar MM: Prevalence, belief and awareness of preferring traditional healthcare system in urban and rural people of Noakhali district, Bangladesh. Int Curr Pharmace J 2012;1:229-234.

54 Uddin MS, Mamun AA, Khanum S, Begum Y, Alam MS: Analysis of in vitro antioxidant activity of Caryota urens L. leaves: a traditional natural remedy. J Coast Life Med 2016;4:483489.

55 Hossain MS, Uddin MS, Asaduzzaman M, Munira MS, Josim M, Uddin M, et al: Inquiry of analgesic and anti-inflammatory activities of Xanthosoma sagittifolium leaves. J Coast Life Med 2017;5:22-26.

56 Nandan D, Gupta VK, Dabral SB, Misra SK, Gupta SC, Prakash B, et al: Role of traditional healers and indigenous medical practitioners in health care. Indian J Pub Heal 1989;33:61.

57 Flaiti MA, Badi KA, Hakami WO, Khan SA: Evaluation of self-medication practices in acute diseases among university students in Oman. J Acute Dise 2014;3:249-252.

58 Sawalha AF: Assessment of self-medication practice among university students in Palestine: therapeutic and toxicity implications. Islam Uni J 2007;15:67-82.

59 Idris T, Khanum S, Uddin MS, Asaduzzaman A, Islam MA, Nasrin F, et al: Study on selfmedication practices among university students of Bangladesh. Br J Med Med Res 2016; $14: 1-8$.

60 Abrha S, Molla F, Melkam W: Self-medication practice: the case of Kolladiba Town, North West Ethiopia. Int J Pharma Sci Res 2014;5:670-676.

61 Kuriakose C, Shifafiya MN, Sekar V, Kumar RS: To evaluate the prevalence and drug prescribing trends in stroke patients: a retrospective study. Int J Che Pharmace Sci 2014;5:22-26.
Disease and Prescription Pattern for Outpatients with Neurological Disorders 